\title{
Modelo multicritério de apoio à decisão sobre o uso de fungos micorrízicos em fabáceas
}

Abordar e compreender melhor as relações solo-planta-microbiota nas ciências agrárias podem melhorar o sucesso da produção e reduzir custos, nesta perspectiva, parece vantajoso desenvolver mecanismos seguros, automatizados, organizados e controláveis no levantamento das evidências e que considere a validade e relevância das afirmativas encontradas. Esta pesquisa teve por objetivo identificar através de um modelo multicritério de apoio à decisão o efeito das interações simbióticas entre fungos micorrízicos (FM) em fabáceas comestíveis com base na literatura atual sobre os possíveis benefícios e dificuldades da agricultura sobre essa interação. Foram realizadas buscas em duas bases de dados: Scopus e Web of Science. Os critérios adotados foram: artigos que apresentaram referência direta aos descritores 'Mycorrhizae' e 'Leguminous or Fabaceae'; artigos de pesquisa publicados entre 2015 e 2020 disponíveis em inglês e que apresenta os descritores primários nos seguintes campos: título (title), resumo (abstract) e palavras-chave (keywords). Como critério de classificação da importância e da similaridade dos artigos estudados foi utilizado o método de escore por ocorrência de descritores e fatores de qualidade tais como: inovação, estrutura e capacidade de transferência da tecnologia, seguindo as recomendações de acordo com o Manual Cochrane de Revisões Sistemáticas de Intervenções. O modelo apresentou resultados positivos do uso de FM em pesquisas relacionadas com a fitorremediação de solos contaminados com chumbo e zinco, aumento da massa vegetal seca, volume de raiz e resistência à salinidade e à inundação. O método utilizado demonstrou fatores positivos e concorrentes na interação de micorrizas arbusculares em fabáceas cultiváveis para destino alimentar.

\section{The cochrane multicriteria support model on the use of mycorrhizal fungi in fabaceae} perspective, it seems advantageous to develop safe, automated, organized and controllable mechanisms in the collection of evidence and which considers validation and get from the statements found. This research aims to identify through a multicriteria model of decision support the effect of symbiotic interactions between Mycorrhizal Fungi (FM) in vegetables classified as edible fabaceas, presenting the current literature on the possible benefits and difficulties of agriculture on this interaction. Searches were carried out in two databases: Scopus and Web of Science. The adopted criteria were: texts that have direct reference to the descriptors 'Mycorrhizae' and 'Leguminous OR Fabaceae'; Research articles; published between 2015 and 2020; available in English and that presents the primary descriptors in at least the following fields: Title (Title), Abstract (Abstract) and Keywords (Keywords). As a criterion for classifying the importance and similarity of the articles studied, the method of scoring by the occurrence of descriptors and quality factors such as: Innovation, Structure and ability to transfer technology was used, following the recommendations according to the Cochrane Manual of Systematic Reviews Interventions. The model showed positive results from the use of FMs, among others the phytoremediation of soils contaminated with lead and zinc, increased dry mass, root volume and resistance to salinity and flooding. The described method demonstrated positive and concurrent factors in the interaction of arbuscular mycorrhizae in cultivable fabaceae for food destination.

Keywords: Microbiology; Endomycorrhizae; Horticulture; Arbuscular Mycorrhizal Symbiosis.

Topic: Ciências do Solo

Reviewed anonymously in the process of blind peer.

Luiz Diego Vidal Santos

Universidade Federal de Sergipe, Brasil

http://lattes.cnpq.br/7491112603328096

http://orcid.org/0000-0001-8659-8557

vidal.center@academico.ufs.br

Francisco Sandro Rodrigues Holanda (ib)

Universidade Federal de Sergipe, Brasil

http://lattes.cnpq.br/7935943969315043

http://orcid.org/0000-0003-3575-8105

fholanda@infonet.com.br

Pedro Vinícius Bertulino Menezes

Universidade Federal de Sergipe, Brasil

http://lattes.cnpq.br/6638272377583717

http://orcid.org/0000-0003-1477-7892

pedroviniciusbm20@gmail.com

DOI: 10.6008/CBPC2179-6858.2021.007.0001
Received: 02/07/2021

Approved: 27/07/2021

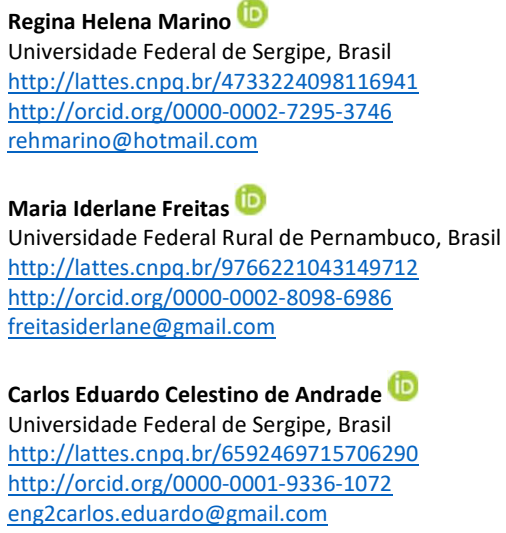

Referencing this:

SANTOS, L. D. V.; HOLANDA, F. S. R.; MENEZES, P. V. B.; MARINO, R. H.; FREITAS, M. I.; ANDRADE, C. E. C.. Modelo multicritério de apoio à decisão sobre o uso de fungos micorrízicos em fabáceas. Revista lbero Americana de Ciências Ambientais, v.12, n.7, p.1-14, 2021. DOI: http://doi.org/10.6008/CBPC2179-6858.2021.007.0001 


\section{INTRODUÇÃO}

A agricultura desempenha um papel singular, pois é a partir desta atividade que são fornecidos alimentos e matéria-prima para diversos setores econômicos. A relevância deste setor para a economia é indiscutível, mesmo diante dos desafios presentes no mundo contemporâneo como a superpopulação, as mudanças das dificuldades a produção agrícola em larga escala e a competição por recursos (RIEGLER, 2018; ROCKSTROM et al., 2017).

As plantas da família Fabaceae quando utilizada como produto alimentar exibem como características marcantes o fato de possuírem baixo teor calórico e alto teor de fibras, bem como podem ser consideradas como fonte de proteína, de ácido fólico e de vitaminas $\mathrm{C}, \mathrm{K}$ e do complexo B (LARRAINZAR et al., 2017). Porém, os desafios da produção deste alimento estão intrinsecamente relacionados à crescente demanda, que caminha de mãos dadas à gradativa elevação da taxa de crescimento populacional e a necessidade de manter uma produção sustentável e eficiente no uso de água e solos (SANTOS et al., 2019).

A produção convencional emprega fertilizantes orgânicos (compostos) e/ou adubos químicos industriais, à base de nitrogênio $(\mathrm{N})$, de fósforo $(\mathrm{P})$ e de potássio $(\mathrm{K})$, os quais são cruciais ao desenvolvimento da maioria das plantas cultiváveis. Entretanto, a demanda crescente destes macronutrientes em formulação industrial por outros setores agrícolas tem elevado os preços destes adubos (BIANCHETTO et al., 2017; FERREIRA et al., 2019), o que eleva o custo de produção e do produto final (RIBEIRO et al., 2017).

Desta forma, a construção da fertilidade do solo e o manejo sustentável de pragas são os pontos principais dos custos da produção destes produtos. Para atingir uma fertilidade desejável do solo e a resistência ao ataque de pragas e doenças é importante a adequada disponibilidade de macronutrientes primários (N, P e K) e secundários (Ca, Mg e S) (BORGES et al., 2016; ZAMBOLIM; et al., 2012). Para isso existem mecanismos de ação que apresentam potencial sinérgico para a indução do melhoramento do solo de forma natural (MAIA, 2016), por meio da ação de micro-organismos como os fungos micorrízicos arbusculares que auxiliam na absorção de água e nutrientes necessários às plantas (MIRANDA et al., 2001; REIS et al., 2012).

A cooperação dos fungos micorrízicos arbusculares no desenvolvimento vegetal ocorre naturalmente na produção agrícola (BINI et al., 2018), como observado em acerola, girassol e amendoim (BALOTA et al., 2011). O efeito benéfico do desempenho das micorrizas sobre o desenvolvimento de plantas depende da disponibilidade de nutrientes (fertilidade natural do solo, adição de fertilizantes orgânicos e químicos), do $\mathrm{pH}$, da ocorrência de compostos tóxicos, da salinidade e da presença de microrganismos nativos (CASTRO et al., 2016; BONFIM et al., 2018), bem como da interação fungo versus planta e da idade da planta.

A atividade de tomada de decisão sobre o uso de novos métodos no meio rural envolve muitas vezes extensas pesquisas em uma grande quantidade de documentos, sendo esta atividade trabalhosa, quando realizada manualmente, o que demora e pode sofrer interpretações equivocadas pelo pesquisador (XIAO et al., 2019). Nesta perspectiva, parece vantajoso desenvolver mecanismos seguros, automatizados, organizados e controláveis no levantamento das evidências e que considere a validade e relevância das 
afirmativas encontradas (IDRI et al., 2018), em especial a seleção de estudos primários sobre o uso de novos produtos para a produção agrícola. Tal mecanismo deve promover ao usuário a otimização do tempo e o trabalho demandado, mantendo a confiabilidade dos resultados (ROCKSTROM et al., 2017).

Um modelo multicritério pode ser compreendido como uma forma de pesquisa de metadados científicos, que se utiliza de informações bibliográficas para obtenção de resultados de pesquisas de outros pesquisadores, com o objetivo de fundamentar teórica e cientificamente um determinado objetivo (ROTHER, 2007). Uma metodologia estruturada em rodadas utilizadas em primeiro estágio para a área de saúde encontrada no livro de Cochrane foi objeto procedimental deste estudo com sucesso de uso em outras áreas (HIGGINS et al., 2018; MAIA et al., 2018; ROSA, 2017; TIKKA et al., 2020).

O modelo multicritério de apoio à decisão em uma revisão sistemática (RS) pode alcançar a originalidade através de meios reprodutíveis de maneira a limitar o espectro de estudo e conjecturar o estado da arte de interesse (KEELE, 2007; MEDEIROS et al., 2015). Desta forma, esta pesquisa tem como objetivo identificar através de um modelo multicritério de apoio à decisão o efeito das interações simbióticas entre fungos micorrízicos e fabáceas comestíveis, com base na literatura atual sobre os possíveis benefícios e dificuldades da agricultura sobre essa interação.

\section{MATERIAIS E MÉTODOS}

Para identificar, avaliar e interpretar resultados relevantes da revisão sistemática em trabalhos publicados foi estabelecido um protocolo preliminar com base no método sistemático Cochrane Central Register of Controlled Trials (BELL et al., 2005) e adaptado para esta pesquisa.

O desenvolvimento das fases deste estudo segue o Manual de Revisões Sistemáticas de Intervenções, utilizando adaptações das sete rodadas descritas pelo manual: (1) Formulação da pergunta, (2) Localização dos estudos (artigos), (3) Seleção dos estudos, (4) Extração dos estudos, (5) Interpretação dos dados e (6) Síntese e atualização da revisão.

\section{Rodada 1: Formulação da pergunta}

Para este estudo foi atribuído o seguinte problema: Os fungos micorrízicos realizam interações simbióticas em fabáceas comestíveis.

\section{Rodada 2: Localização dos estudos}

Na segunda rodada foi realizada uma busca com descritores primários nas bases de dados Scopus (Elsevier) e Web of Science (Clarivate Analytics). Como estratégia para busca da produção acadêmica a ser utilizada nesta rotina, foram definidos descritores primários utilizando a lógica baseada em termos centrais. Os descritores foram trabalhados na língua inglesa vinculados por operadores booleanos (AND, OR e NOT), seguindo as regras descritas por Slamet et al. e vinculados ao tema proposto. Os descritores primários adotados foram 'Mycorrhizae*' e 'Leguminous OR Fabaceae'. 
O critério de inclusão e exclusão para esta rodada das recomendações foi aceitar apenas artigos completos. O intervalo de tempo utilizado na pesquisa foi definido de 2015 a 2020, ou seja, nos últimos 5 anos, que foram escritos na língua inglesa e que apresentam os descritores primários nos seguintes campos: título (title), resumo (abstract) e palavras-chave (keywords).

\section{Rodada 3: Seleção dos estudos}

A seleção inicial dos estudos foi realizada em sua primeira fase utilizando a "Seleção automática de citação de pontuação" (SCAS) (COSTA et al., 2015; OCTAVIANO et al., 2015) com o emprego do software StArt (State of the Art through Systematic Review).

Aos artigos que não apresentaram quantidade de referências significativas para análise pelo SCAS foram adotados critérios de Inclusão/Exclusão os quais estão dispostos no Quadro 1, onde cada artigo deve apresentar no mínimo dois critérios de Inclusão para que possa ser elegível à próxima rodada.

Os demais trabalhos são considerados automaticamente inelegíveis para a próxima rodada. Todas as seleções nesta rodada foram realizadas por dois pesquisadores, de forma independente e restrita a fim de evitar influência pessoal nos resultados.

Quadro 1: Critérios de Inclusão/Exclusão dos artigos observados.

\begin{tabular}{|l|l|}
\hline Critérios & Grupo de Índice \\
\hline $\begin{array}{l}\text { Aborda os dois descritores primários e apresenta relação entre os descritores primários “Fungos micorrízicos } \\
\text { e fabáceas” }\end{array}$ & Inclusão/Exclusão \\
\hline Periódico com fator de impacto internacional & Inclusão/Exclusão \\
\hline Correlação entre as duas áreas temáticas & Inclusão/Exclusão \\
\hline Descreve as variáveis analisadas & Inclusão/Exclusão \\
\hline Possibilidade de replicação do experimento & Inclusão/Exclusão \\
\hline Trabalho sobre o tema proposto na pergunta & Inclusão/Exclusão \\
\hline Ineditismo da pesquisa junto ao corpo textual & Inclusão/Exclusão \\
\hline É uma pesquisa experimental & Inclusão/Exclusão \\
\hline Aderência aos descritores primários & Inclusão/Exclusão \\
\hline Correlação entre as áreas de estudo da pergunta & Inclusão/Exclusão \\
\hline Apresenta linguagem clara sobre o assunto & Inclusão/Exclusão \\
\hline
\end{tabular}

\section{Rodada 4: Extração dos estudos}

Após a rodada de seleção dos estudos onde foram aceitos os artigos que apresentaram ao menos dois critérios para inclusão, estes trabalhos passaram para a fase de extração dos dados, na qual foi realizada uma prospecção mais aprofundada sobre cada trabalho aceito, onde foram classificados os trabalhos que abordam especificamente a pergunta descrita na primeira rodada 'Os fungos micorrízicos realizam interações simbióticas em fabáceas comestíveis?'.

A seleção ocorreu de forma manual a fim de que fosse possível realizar uma leitura mais aprofundada, buscando a compreensão de todo o conteúdo desenvolvido nos manuscritos assim como a relação de causa/efeito dos fungos micorrízicos arbusculares em fabáceas estudadas ou não as tem como foco do experimento. Nesta fase foram excluídos os manuscritos que apresentavam relativas similaridades com os demais, assim como trabalhos que mantinham caráter de continuidade de uma pesquisa macro, pelos mesmos autores ou grupo de pesquisa. 
Para compreender a relação de citação de trabalhos e a participação dos autores das áreas de pesquisa relacionadas com o tema, nesta rodada foram analisadas redes de participação e citações baseadas em dados bibliométricos. Para isso foi utilizado o programa VOSviewer ${ }^{\circledast}$ v.1.6.13 (WONG, 2018), o que permite compreender que grupo de autores estão envolvidos nas principais pesquisas da área, quais trabalhos mais descrevem o cluster formado e que temas são mais pertinentes na série temporal escolhida (2015-2020).

\section{Rodada 5: Análise e interpretação dos dados}

Na análise e interpretação dos dados foi utilizado como método a análise qualitativa dos dados textuais por meio do desenvolvimento de códigos de indicadores utilizando para isto o software ATLAS.ti (GARCÍA et al., 2017). Foram considerados novos códigos de descrição relacionados às informações dos trabalhos analisados (Quadro 2).

Quadro 2: Códigos de descrição selecionados nesta fase.

\begin{tabular}{|l|l|l|}
\hline Siglas & Códigos & Grupo de Índice \\
\hline DLG & Descrição da localização geográfica do experimento & Índices de descrição \\
\hline DME & Descrição do método estatístico utilizado & Índices de descrição \\
\hline DPF & Descrição do método/meios de propagação do fungo & Índices de descrição \\
\hline EBE & Efeito benéfico observado & Índices de descrição \\
\hline EFC & Efeito concorrente e limitante observado & Índices de descrição \\
\hline EFM & Espécie de fungo micorrízico arbuscular & Índices de descrição \\
\hline ELE & Espécie de fabaceae utilizada & Índices de descrição \\
\hline PIN & Perfil de Inovação & Índices de descrição \\
\hline TER & Tecnologia direcionada a extensão rural & Índices de descrição \\
\hline
\end{tabular}

\section{Rodada 6: Síntese e atualização da revisão}

A última rodada foi responsável pela classificação por qualidade dos trabalhos selecionados. Este método possibilitou compreender melhor a correlação entre os termos mais frequentes, as áreas de pesquisa assim como os objetivos de estudos mais frequentes.

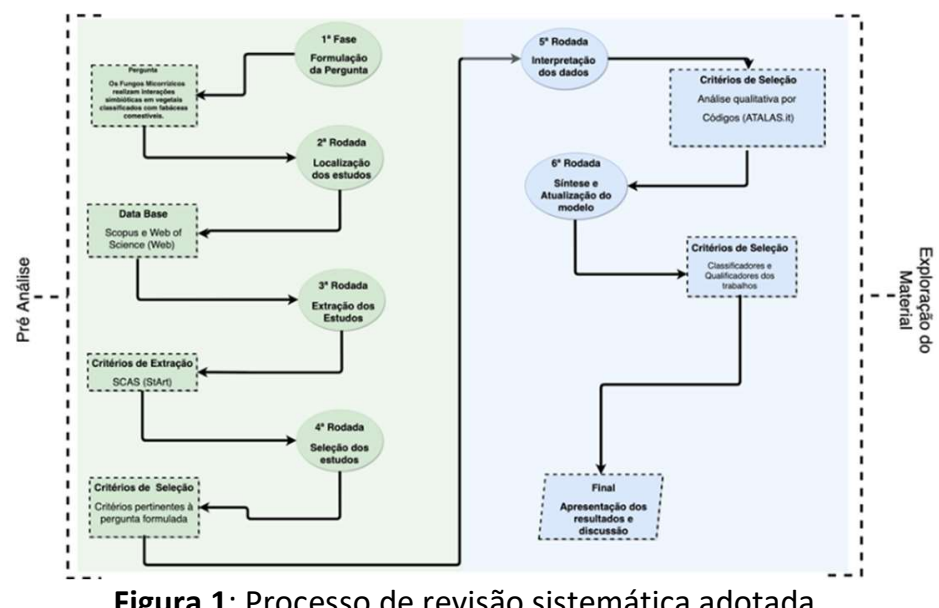

Para cumprir este objetivo foram elaboradas para classificação de dados três descritores primários e seus respectivos descritores secundários: Classificação de uso da fabaceae (Arbórea não alimentícia, uso ornamental, alimentação humana, alimentação para animais domésticos e engenharia 
natural/bioengenharia), Tipo de micorriza descrito (Ectomicorriza, ectendomicorriza, micorriza arbuscular e ericaceae).

Para a descrição de qualidade dos trabalhos foram selecionados cinco descritores: Apresenta capacidade de reprodução (1 a 5 ), se trata de inovação $(S / N)$, apresenta custos de produção $(S / N)$, demonstra benefícios de uso dos FMs (S/N) e fator de impacto segundo Qualis capes 2016 para a área de avaliação Agricultura I. Na Figura 1 é possível visualizar todo o processo de modelo multicritério de apoio à decisão sobre o uso de fungos micorrízicos em fabáceas.

\section{RESULTADOS E DISCUSSÃO}

$\mathrm{Na}$ fase de Localização dos estudos foram encontrados 426 artigos de pesquisa e de revisão que abordam a pergunta 'Os fungos micorrízicos realizam interações com fabáceas?' no período de 2015 (95 artigos), 2016 (74 artigos), 2017 (62 artigos), 2018 (59 artigos), 2019 (82 artigos) e 2020 (57 artigos). Deste total, cinco trabalhos foram excluídos por estarem duplicados na verificação de duplicidade do software StArt.

Todos os artigos minerados nos bancos de dados (426 artigos) que emergiram utilizando os descritores de busca foram inicialmente considerados elegíveis para avançar para a rodada 3 que é a seleção dos estudos. Deste total o sistema SCAS excluiu automaticamente 186 artigos por não apresentar valores acima de 0.6 assim como mais 26 trabalhos por se tratar de revisão bibliográfica.

O método aceitou 68 artigos automaticamente, sendo que do corpo textual restante (246 artigos) 146 que não foram classificados pelo método por não apresentar quantidade de referências bibliográficas substanciais para ser selecionado pelo SCAS, porém apresentavam possibilidades de classificação manual seguindo desta forma para serem selecionados manualmente. Os trabalhos que surgiram nesta fase da rodada de seleção abordam majoritariamente sobre interações benéficas da simbiose, e a abundância dos fungos micorrízicos arbusculares em diferentes solos (XIAO et al., 2019) assim como as interações cruzadas com bactérias fixadoras de nitrogênio (BAĞDATLI et al., 2019).

Dos 146 trabalhos que foram conduzidos para averiguação manual na rodada anterior, 114 foram considerados elegíveis pois apresentaram ao menos dois critérios de Inclusão/Exclusão ${ }^{1}$ e os descritores primários no título², resumo e nas palavras-chave os demais (32 artigos) foram excluídos para a próxima rodada. Na Tabela 1 é possível visualizar a quantidade de trabalhos que foram classificados pelos critérios de inclusão/exclusão.

Os 200 artigos elegíveis na rodada de seleção foram direcionados para a rodada de extração dos estudos, objetivando a construção do diagrama VOSviewer. Por meio do diagrama foram identificadas 371 redes de conexão entre os trabalhos e autores, dos quais 194 trabalhos foram no mínimo três vezes citados, surgindo assim 56 nós (conexões cruzadas) que exibem 8 clusters.

\footnotetext{
${ }^{1}$ Critérios descritos no Quadro 1

2 Mycorrhizae, Leguminous ou Fabaceae. 
Tabela 1: Quantidade de trabalhos avaliados pelos critérios de inclusão/exclusão.

\begin{tabular}{|c|c|}
\hline Critérios de Inclusão/Exclusão & $\begin{array}{l}\text { No de } \\
\text { artigos }\end{array}$ \\
\hline $\begin{array}{l}\text { Aborda os dois descritores primários e apresenta relação entre os descritores primários 'Fungos micorrízicos e } \\
\text { fabáceas' }\end{array}$ & 45 \\
\hline Periódico com fator de impacto internacional & 50 \\
\hline Correlação entre as duas áreas temáticas & 80 \\
\hline Descreve as variáveis analisadas & 114 \\
\hline Alta possibilidade de replicação do experimento & 90 \\
\hline Trabalho sobre o tema proposto na pergunta & 82 \\
\hline Ineditismo da pesquisa junto ao corpo textual & 100 \\
\hline É uma pesquisa experimental & 32 \\
\hline Aderência aos descritores primários & 99 \\
\hline Correlação entre as áreas de estudo da pergunta & 102 \\
\hline Apresenta linguagem clara sobre o assunto & 80 \\
\hline
\end{tabular}

O software VOSviewer utiliza uma técnica própria para agrupamento (WALTMAN et al., 2010), como o método SCAS. Entretanto, o VOSviewer utiliza como base as relações de citação entre os clusters, o que difere do SCAS, o que resulta uma visualização interativa com informações adicionais não visíveis no método anterior.

A Figura 2 apresenta o agrupamento formado pelos 8 clusters resultantes do corpo textual, eles estão descritos em cores distintas ou seja: vermelho, verde, azul, amarelo, laranja, ciano, marrom e magenta, os quais representam as correlações dos trabalhos publicados pelos principais autores e as áreas de estudo das pesquisas desenvolvidas (VAN ECK et al., 2017).

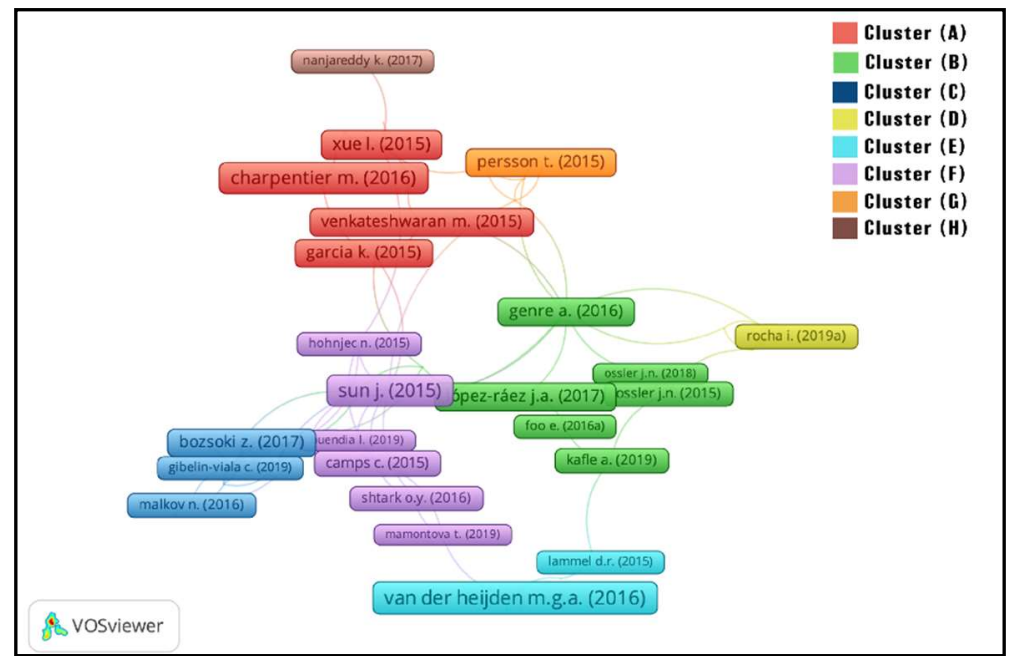

Figura 2: Relação de agrupamentos de artigos encontrados com os principais autores e áreas de estudo relacionados com a simbiose planta versus fungos micorrízicos Arbusculares.

Os clusters A e o cluster B de cores vermelho e verde respectivamente emergiram de artigos que descrevem pesquisas sobre as características genéticas que são responsáveis pela simbiose. 0 surgimento de dois clusters distintos com o mesmo tema se deu pela emergência de dois nós resultantes de artigos de diferentes autores os quais não se citam, formando assim dois clusters de cores distintas.

O cluster $\mathrm{C}$ de cor azul representa os manuscritos referentes aos sinais e às vias metabólicas, enquanto o cluster $D$ representado pela cor amarela englobou publicações sobre a interação fúngica com a planta hospedeira. 
Os clusters E de cor ciano trata sobre ação dos Fungos Micorrízicos objetivando a fixação de nitrogênio na planta e o cluster $\mathrm{F}$ de cor magenta que os trabalhos relacionados com a associação de fungos micorrízicos arbusculares e as rizobactérias, respectivamente. E os clusters $\mathrm{G}$ e H de cores laranja e marrom expressaram os manuscritos que tratavam sobre 'feedback' planta-solo e controle de estresse hídrico.

É importante notar que, mesmo agrupadas na forma em que áreas de interesse das pesquisas não se relacionem diretamente, os garfos de conexão interagem formando uma cadeia de referências entre os diversos pesquisadores/trabalhos. Este comportamento se nota quando é observado o principal cluster A estritamente agrupado com o cluster B, os quais descrevem as características genéticas dos FMAs, e se relacionam diretamente com os trabalhos presentes no cluster $C$ que descreveram sinalizadores, vias moleculares e metabólicas para colonização fúngica e efetiva simbiose com a planta hospedeira.

A exemplo da integração entre os três primeiros cluster A, B e C pode ser citado o trabalho de Garcia et al. (2015) pertencente ao Cluster A, em que demonstrou o papel das proteínas efetoras responsáveis por suprimir as defesas da planta, bem como por sinalização da planta hospedeira durante a colonização fúngica (MONTE et al., 2019), enquanto os fungos micorrízicos arbusculares (FMA) regulam as defesas do hospedeiro pela manipulação de vias hormonais vegetais (GARCIA et al., 2015). Assim, o entendimento das vias de simbiose é necessário para compreender o estabelecimento da efetiva simbiose FMA versus fabáceas, o qual pode ser um fator decisivo para várias respostas benéficas de longo prazo na planta.

No cluster B, o trabalho desenvolvido por Xue et al. (2019), a fabácea Lotus japonicus apresenta um modelo no qual, genético no qual a via de sinalização da simbiose comum se mostra como a primeira via de estabelecimento da simbiose, promovendo a reprogramação celular da raiz, possibilitando a colonização preferencial por fungos FMAs, que formam uma densa rede de hifas intraradical com arbusculares de fungos não Micorrízicos.

No cluster C, a interação FMA x Planta hospedeira, as auxinas, os brassinosteroides, as estrigolactonas, as citocininas, o ácido abscísico e o ácido jasmônico são hormônios que colaboraram efetivamente para a simbiose (NAGAE et al., 2015; VENKATESHWARAN et al., 2015).

Por sua vez, no cluster D que trata sobre a interação fúngica com a planta hospedeira, Bâ et al. (2015) afirmaram que a interação FMA e planta hospedeira favoreceu a tolerância ao alagamento em mudas, provavelmente devido ao aumento do número de lenticelas, de raízes adventícias e de aerênquima.

Responsável pelo desenvolvimento do Cluster E, o trabalho de Rocha et al. (2019) afirma que a associação de FMA Funneliformis mosseae e a fabaceae Vigna unguiculata promoveu aumento do teor de nitrogênio e fósforo na biomassa vegetal, tal como também observado por Oliveira et al. (2017) na massa das sementes e no rendimento das sementes comportamentos similares aos estudados por Rocha et al. (2019). Entretanto, é importante observar que sob alta disponibilidade de $\mathrm{P}$ a simbiose micorrízica não demonstra influência na absorção deste nutriente demonstrando que, a eficiência da associação vai depender do objetivo da cultura e o contexto ambiental. O mesmo comportamento foi também observado no trabalho de_Ballhorn et al. (2016) Bakhshandeh et al. (2017) ambos pertencentes ao mesmo cluster. 
Os clusters $\mathrm{F}$ tem por trabalho explicativo a pesquisa de Püschel et al. (2017) que estudando a colonização micorrízica em associação com o Rhizophagus irregularis promoveram uma correlação fortemente positiva com o teor de fósforo na biomassa da fabaceae Medicago truncatula o que demonstra a importância desse elemento na simbiose.

Nos clusters G e H correlacionados com o feedback planta-solo e controle de estresse, respectivamente, os trabalhos de Zhang et al. (2019) (Cluster G) que trata da resposta positiva sobre influência da planta ao período de seca, assim como o trabalho de Garg et al. (2016) (Cluster H), que estudaram a salinidade como fator de restrição na produtividade das fabáceas, constataram que as interações fúngicas aumentaram a tolerância ao sal através de uma mudança na dinâmica da destruição oxidativa para um sistema de defesa antioxidante favorável em plantas fabáceas, tais como o grão de bico submetido a estresse. Estes trabalhos destacaram o uso benéfico dos FMAs ajudando as fabáceas a superar diversos tipos de estresses, desde salinos (AL-FARSI et al., 2020), hídricos (FAKHECH et al., 2019) e químicos (REN et al., 2016).

Por meio da leitura crítica dos 123 manuscritos elegíveis para esta rodada foi possível selecionar 67 publicações que contemplam objetivos descritos na pesquisa. As 56 publicações restantes não foram elegíveis para a análise final por não apresentar aderência dos conteúdos com a pergunta proposta, característica de agrupamento de conteúdo para mesmos autores e conteúdos pouco inovadores.

Nas rodadas de interpretação dos dados (rodada 5) e da síntese da revisão (rodada 6), a maior parte dos estudos empregou amostragem por testes de diferenças de médias (38), modelos lineares de efeitos mistos e similares (26) e teste de razão de verossimilhança (3). Nenhum estudo atendeu a todos os códigos de qualidade, por não apresentarem custos do desenvolvimento e citação direta a possibilidade de transferência de tecnologia aos produtores rurais, em geral apresentando vieses na seleção do ambiente e população experimentada.

Em relação aos códigos adotados pelo método de análise qualitativa dos dados textuais foi possível observar os principais resultados nos diversos experimentos apresentados nos artigos selecionados conforme listados no Quadro 3.

Quadro 3: Síntese da abordagem usando os códigos descritos na rodada 5.

\begin{tabular}{ll}
\hline Código & Resumo da aplicação dos códigos \\
\hline DLG: & A maioria dos experimentos observados foram realizados em casas de vegetação, apenas três trabalhos foram realizados \\
DME: & $\begin{array}{l}\text { Nas análises estatísticas foram utilizados testes lineares de efeitos mistos (Imer) e modelos lineares generalizados de } \\
\text { efeitos mistos (glmer) e teste de variância de médias (ANOVA) sendo de uma ou várias vias (XIAO et al., 2019). }\end{array}$ \\
DPF: & A atividade de determinação de espécies micorrízicas variou conforme o objetivo da pesquisa: a) Para a determinação \\
& de genes foram utilizados métodos de análise filogenética de sequências de proteínas codificadas (MALKOV et al., 2016); \\
b)coloração histoquímica e microscopia para visualizar atividade enzimática nas regiões com atividade do promotor & (NAGAE et al., 2015); c) para isolamento de espécies, os métodos mais citados foram os que utilizam separações por \\
centrifugação de sacarose e peneira manual (MAHDHI et al., 2019); d) Quanto a atividade de inoculação foi observado \\
o desenvolvimento de misturas de hifas internas e externas e esporos (GARCíA-PARISI et al., 2017), amostras de solos \\
contendo esporos e hifas et al., 2018), cultivo dos esporos em ágar manitol com extrato de levedura (REN et al., 2016). \\
Considerando que as respostas das plantas à micorrização variam em função da espécie de planta e de fungo micorrízico, \\
pode-se citar que os efeitos benéficos desta simbiose citados nos trabalhos selecionados foram: a) aumento significativo \\
a alta capacidade de ação dos fungos em variados tipos de solos e alta capacidade de associação simbiótica às fabáceas \\
(BAĞDATLI et al., 2019; GARG et al., 2016; MAHDH et al., 2019); b) Influência significativa no crescimento vegetal \\
avaliado pela massa seca da raiz, comprimento da raiz, diâmetro da raiz, teor de clorofila, e volume e número das
\end{tabular}


vagens (GARG et al., 2016; MARZBAN et al., 2017; ROCKSTROM et al., 2017); c) Melhor absorção e fixação dos macro e micronutrientes (GARG et al., 2016; GOMES et al., 2020; ZHANGA et al., 2019); d) Capacidade de trabalho sinérgico com rizobactérias (HACK et al., 2019; KOHLER et al., 2015); e) Produção de Lipochitooligossacarídeos (LCOs) que induz ao aumento de pelos radiculares (COPE et al., 2019); f) Tolerância a solos salinos (BÂ et al., 2015; GARG et al., 2015); g) Resistência a inundações com surgimento de raízes adventícias, tecido de aerênquima e lenticelas em raízes submersas e h) fitorremediação de solos contaminados com chumbo e zinco (YANG et al., 2015).

EFC: $\quad$ Para efeitos concorrentes e limitantes foram descritos para colonização micorrízica: a) com o uso intensivo do solo e a alta concentração de P (HAILEMARIAM et al., 2018; PALTA et al., 2018); b) presença de fungos endofíticos (Epichloë spp., Ascomycota: Clavicipitaceae) (GARCÍA-PARISI et al., 2017); c) excesso de água (SÁNCHEZ et al., 2020); d) deficiência na sinalização inicial devido a presença de mutantes de simbiose defeituosos que impedem o reconhecimento do simbionte e bloqueia a entrada de simbiontes fúngicos e bacterianos nas raízes do hospedeiro (NAGAE et al., 2015).

EFM: As espécies fúngicas que mais apresentaram experimentos com resultado positivo na interação com as fabácias foram: Funneliformis mosseae, Glomus mosseae, Glomus hoi S.M. Berch and Trappe, Rizoglomus intraradices, Funneliformis mosseae e Claroideoglomus claroideum, Funneliformis mosseae e Rhizophagus irregularis.

ELE: As principais espécies de fabáceas apresentadas nos trabalhos e que demonstraram efeitos positivos resultantes da interação fúngica arbuscular foram: Vicia sativa, Vicia faba e Medicago sativa, Cajanus cajan, Phaseolus vugaris, Lotus japonicus e Medicago truncatula

PIN: $\quad$ Alguns estudos apresentaram métodos e resultados inovadores quanto aos estudos dos FMAs podendo ser citados o trabalho de (JANOUŠKOVÁ et al., 2015), que abordam um método de quantificação de DNA fúngico presente nos tecidos vegetais a partir de material vegetal seco. Foi possível alocar para esse código os trabalhos que tratam sobre a identificação de mecanismos responsáveis pela modulação do estabelecimento da simbiose entre FMA e fabáceas como a) presença do ácido abscísico que pode controlar os níveis de colonização (BANASIAK et al., 2020; STEC et al., 2016); b) Células de raízes de leguminosas mostram oscilações de Ca2+ nuclear em resposta a moléculas de sinalização de rizobactérias fixadoras de nitrogênio e fungos micorrízicos arbusculares (FMA) .

TER: $\quad$ Alguns experimentos observados foram conduzidos em campo com intuito de transferir a tecnologia como citado no trabalho de Haro et al. (2018) com o emprego de FMA nativos da região Burkina Faso - África em associação com a fabaceae Vigna unguiculata

Para efeito de compreensão sobre causa e efeito resultante dos experimentos estudados, os nove códigos foram agrupados em duas categorias principais: efeitos benéficos e efeitos concorrentes (Figura 3).

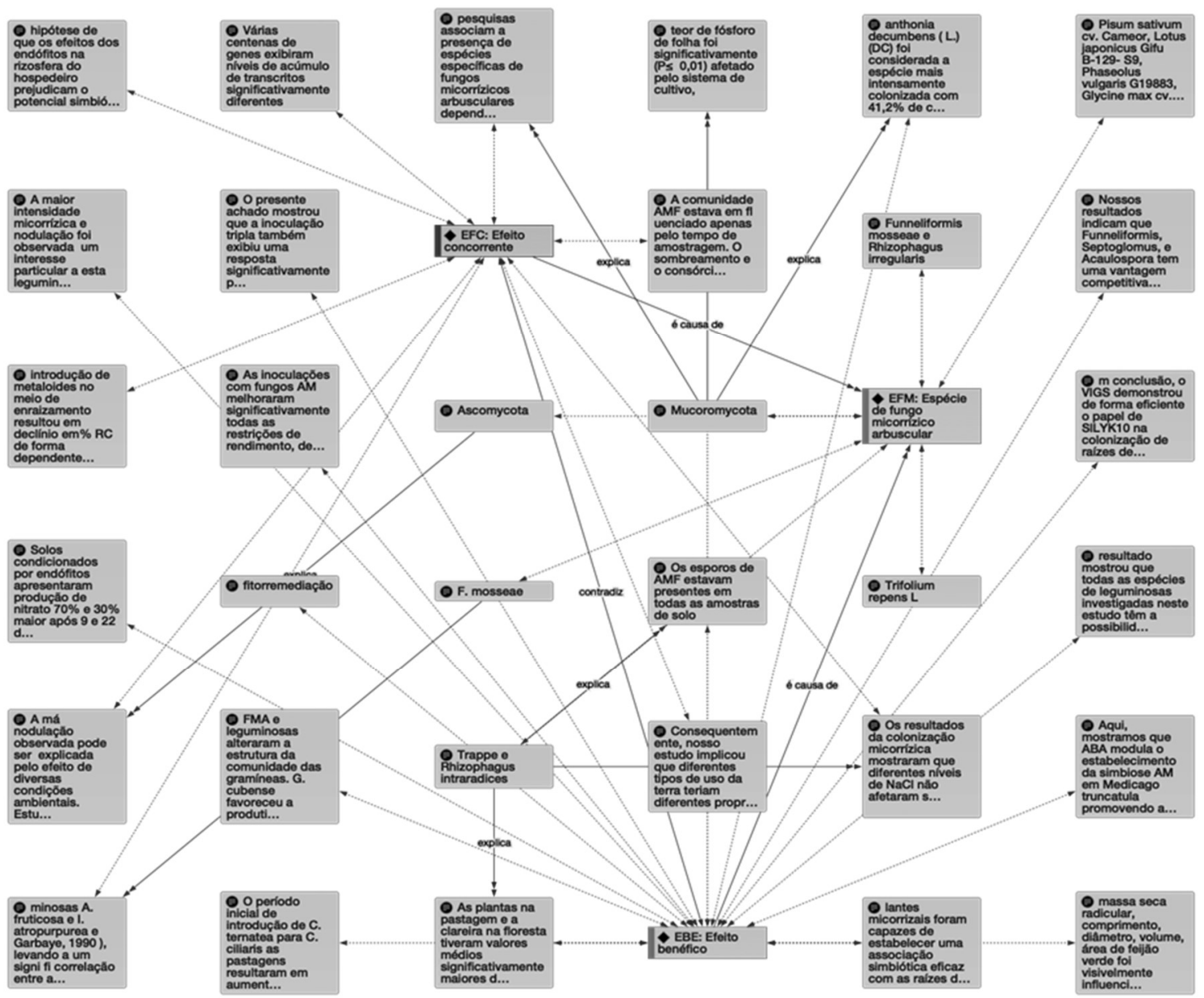

Figura 3: Relação entre os códigos e os trechos pertinentes às considerações relacionadas ao benefício e aos FMAs com uso do software Atlas.ti. 
Como todas as ferramentas de busca, classificação, análise, estatística e categorização utilizadas nesta abordagem são disponibilizadas gratuitamente ou para uso acadêmico, esta pesquisa pode ajudar inventores, pesquisadores e instituições de ensino e pesquisa a alcançarem novos níveis de desenvolvimento científico e tecnológico.

\section{CONCLUSÕES}

Essa análise apresenta através de um modelo multicritério de apoio à decisão uma compreensão significativa sobre as principais interações simbióticas entre fungos micorrízicos (FM) em fabáceas comestíveis, identificando assim potenciais oportunidades futuras de uso deste tipo de fungo para a agronomia sustentável e a Indústria de fertilizantes orgânicos.

O modelo multicritério de apoio a decisão sobre o uso de fungos micorrízicos em fabáceas, demonstrou ser eficaz na extração, avaliação, organização e disponibilização de dados sobre pesquisa científica assim como tecnologias, e se mostra eficiente à medida que reduz o tempo gasto com prospecção e análise substancial dos materiais, trazendo praticidade e rapidez à análise.

O modelo mostra-se facilmente replicável, o qual pode ser utilizado para avaliar outras informações pertinentes à agricultura de acordo com o interesse.

Por meio do modelo elaborado nesta pesquisa foi possível identificar informação que demonstra que, a inoculação micorrízica em fabáceas pode apresentar uma resposta significativamente positiva ao desenvolvimento e crescimento da leguminosa, melhorar as propriedades físicas, químicas e biológicas do solo, propiciando melhor desempenho vegetativo da cultura e de outras espécies que possam estar integradas.

Os resultados desta pesquisa sugerem que a combinação dos fungos micorrízicos com tratos culturais e manejos adequados pode ter um papel potencial para aumentar a produtividade e reduzir perdas econômicas, além de impactar minimamente o meio ambiente deve ser apresentada com as principais contribuições do estudo.

Como em qualquer estudo, há limitações. Primeiro, dois grandes bancos de dados foram pesquisados; embora eles tenham retornado muitos artigos que explicam comportamentos de interação dos fungos, é possível que alguns artigos não tenham sido encontrados e incluídos no corpo textual analisado nesta pesquisa. Pesquisas futuras devem se concentrar em mais estudos comparativos e em outros bancos de dados, inserindo cortes temporais de maior escala de interações em geral, entre os fungos e fabaceas.

\section{REFERÊNCIAS}

AL-FARSI, S. M.; NAWAZ, A.; REHMAN, A. U.; NADAF, S. K.; AL-SADI, A. M.; SIDDIQUE, K. H. M.; FAROOQ, M.. Effects, tolerance mechanisms and management of salt stress in lucerne (Medicago sativa). Crop and Pasture Science, v.71, n.5, p.411-428, 2020. DOI: http://doi.org/10.1071/CP20033

BÂ, A. M.; RIVERA-OCASIO, E.. Genetic Diversity and Functional Traits of Pterocarpus officinalis Jacq. Associated with Symbiotic Microbial Communities in Caribbean Swamp
Forests in Relation to Insular Distribution, Salinity and Flooding. Wetlands, v.35, n.3, p.433-442, 2015. DOI: http://doi.org/10.1007/s13157-015-0651-5

BAĞDATLI, M. C.; ERDOĞAN, O.. Effects of Different Irrigation Levels and Arbuscular Mycorrhizal Fungi (AMF), Photosynthesis Activator, Traditional Fertilizer on Yield and Growth Parameters of Dry Bean (Phaseolus Vulgaris L.) in Arid Climatic Conditions. Communications in Soil Science 
and Plant Analysis, v.50, n.5, p.527-537, 2019. DOI: http://doi.org/10.1080/00103624.2019.1566919

BAKHSHANDEH, S.; CORNEO, P. E.; MARIOTTE, P.; KERTESZ, M. A.; DIJKSTRA, F. A.. Effect of crop rotation on mycorrhizal colonization and wheat yield under different fertilizer treatments. Agriculture, Ecosystems and Environment, v.247, p.130-136, 2017. DOI:

http://doi.org/10.1016/i.agee.2017.06.027

BALLHORN, D. J.; SCHÄDLER, M.; ELIAS, J. D.; MILLAR, J. A.; KAUTZ, S.. Friend or foe-light availability determines the relationship between mycorrhizal fungi, rhizobia and Lima Bean (Phaseolus lunatus L.). PLoS One, v.11, n.5, p.e0154116, 2016.

BALOTA, E. L.; MACHINESKI, O.; STENZEL, N. M. C.. Resposta da acerola à inoculação de fungos micorrízicos arbusculares em solo com diferentes níveis de fósforo. Bragantia, v.70, n.1, p.166-175, 2011. DOI: http://doi.org/10.1590/S000687052011000100023

BANASIAK, J.; BORGHI, L.; STEC, N.; MARTINOIA, E.; JASIŃSKI, M.. The Full-Size ABCG Transporter of Medicago truncatula Is Involved in Strigolactone Secretion, Affecting Arbuscular Mycorrhiza. Frontiers in Plant Science, v.11, 2020. DOI: http://doi.org/10.3389/fpls.2020.00018

BELL, R. F.; DAHL, J. B.; MOORE, R. A.; KALSO, E.. Perioperative ketamine for acute post-operative pain: a quantitative and qualitative systematic review (Cochrane review). Acta Anaesthesiologica Scandinavica, v.49, n.10, p.1405-1428, 2005. DOI: http://doi.org/10.1111/j.1399$\underline{6576.2005 .00814 . x}$

BIANCHETTO, R.; FONTANIVE, D. E.; CEZIMBRA, J. C. G.; KRYNSKI, Â. M.; RAMIRES, M. F.; ANTONIOLLI, Z. I.; SOUZA, E. L.. Desempenho agronômico de milho crioulo em diferentes níveis de adubação no Sul do Brasil. Revista Eletrônica Científica da UERGS, v.3, n.3, p.528-545, 2017. DOI: http://doi.org/10.21674/2448-0479.33.528-545

BINI, D.; SANTOS, C. A.; SILVA, M. C. P.; BONFIM, J. A.; CARDOSO, E. J. B. N.. Intercropping acacia mangium stimulates AMF colonization and soil phosphatase activity in eucalyptus grandis. Scientia Agricola, v.75, n.2, p.102-110, 2018. DOI: http://doi.org/10.1590/1678-992x-2016-0337

BORGES, I. D.; FRANCO, A. R.; KONDO, M. K.; MARTINS, D. C.; TEIXEIRA, E. C.; MORREIRA, S. G.. Acúmulo de macronutrientes na cultura do sorgo granífero na safrinha. Revista Brasileira de Milho e Sorgo, v.15, n.2, p.294-304, 2016.

BONFIM, M. V. L. P.; SILVA, D. K. A.; MAIA, L. C.; YANOMELO, A. M.. Mycorrhizal benefits on native plants of the Caatinga, a Brazilian dry tropical forest. Symbiosis, v.74, n.2, p.79-88, 2018. DOI: http://doi.org/10.1007/s13199-017$\underline{0510-7}$

CASTRO, C. S.; LOBO, U. G. M.; RODRIGUES, L. M.; BACKES, C.; SANTOS, A. J. M.. Eficiência de utilização de adubação orgânica em forrageiras tropicais. Journal of Neotropical Agriculture, v.3, n.4, p.48-54, 2016.

COPE, K. R.; BASCAULES, A.; IRVING, T. B.; VENKASTESHWARAN, M.; MAEDA, J.; GARCIA, K.; RUSH, T. A.; MA, C.; LABBÉ, J.; JAWDY, S.; STEIGERWALD, E.; SETZKE, J.; FUNG, E.; SCHNELL, K.; WANG, Y.; SCHLIEF, N.; BUCKING, H.; STRAUSS, S. H.; MAILLET, F.; JARGEAT, P.; BÉCARD, G.; PUECH-PAGÈS, V.; ANÉ, J.-M.. The ectomycorrhizal fungus laccaria bicolor produces lipochitooligosaccharides and uses the common symbiosis pathway to colonize populus roots. Plant Cell, v.31, n.10, p.2386-2410, 2019. DOI: http://doi.org/10.1105/tpc.18.00676

COSTA, A. B.; ZOLTOWSKI, A. P. C.; KOLLER, S. H.; TEIXEIRA, M. A. P.. Construção de uma escala para avaliar a qualidade metodológica de revisões sistemáticas. Ciência \& Saúde Coletiva, v.20, n.8, p.2441-2452, 2015. DOI: http://doi.org/10.1590/1413-81232015208.10762014

FAKHECH, A.; MANAUT, N.; OUAHMANE, L.; HAFIDI, M.. Contributions of indigenous arbuscular mycorrhizal fungi to growth of retama monosperma and acacia gummifera under water stress (case study: essaouira sand dunes forest). Journal of Sustainable Forestry, v.38, n.7, p.686-696, 2019. DOI: http://doi.org/10.1080/10549811.2019.1602057

FERREIRA, N. C. F.; DUARTE, J. R. M.; OLIVEIRA, L. A. B.; SILVA, E. C.; CARVALHO, I. A.. O papel das matas ciliares na conservação do solo e água. Biodiversidade, v.18, n.3, p.171-180, 2019.

GARCIA, K.; DELAUX, P. M.; COPE, K. R.; ANÉ, J. M.. Molecular signals required for the establishment and maintenance of ectomycorrhizal symbioses. New Phytologist, v.208, n.1, p.79-87, 2015. DOI: http://doi.org/10.1111/nph.13423

GARCÍA, L. M.; PARDO-HERNANDEZ, H.; GUZMAN, E. N. SUPERCHI, C.; BALLESTEROS, M.; MCFARLANE, E.; PENMAN, K.; POSSO, M.; FIGULS, M. R.; SANABRIA, A. J.; SELVA, A.; VERNOOIJ, R. W. M.; ALONSO-COELLO, P.. Development of a prioritisation tool for the updating of clinical guideline questions: the UpPriority Tool protocol. BMJ Open, v.7, n.8, p.e017226, 2017.

GARCÍA-PARISI, P. A.; LATTANZI, F. A.; GRIMOLDI, A. A.; DRUILLE, M.; OMACINI, M.. Three symbionts involved in interspecific plant-soil feedback: epichloid endophytes and mycorrhizal fungi affect the performance of rhizobia-legume symbiosis. Plant and Soil, v.412, n.1-2, p.151-162, 2017. DOI: http://doi.org/10.1007/s11104-016-3054-3

GARG, N.; BHANDARI, P.. Silicon nutrition and mycorrhizal inoculations improve growth, nutrient status, $\mathrm{K}+/ \mathrm{Na}+$ ratio and yield of Cicer arietinum $L$. genotypes under salinity stress. Plant Growth Regulation, v.78, n.3, p.371-387, 2016 DOI: http://doi.org/10.1007/s10725-015-0099-x

GARG, N.; PANDEY, R.. Effectiveness of native and exotic arbuscular mycorrhizal fungi on nutrient uptake and ion homeostasis in salt-stressed Cajanus cajan L. (Millsp.) Enotypes. Mycorrhiza, v.25, n.3, p.165-180, 2015. DOI: http://doi.org/10.1007/s00572-014-0600-9

GOMES, M. P.; MARQUES, R. Z.; NASCENTES, C. C.; SCOTTI, M. R.. Synergistic effects between arbuscular mycorrhizal fungi and rhizobium isolated from As-contaminated soils on the As-phytoremediation capacity of the tropical woody legume Anadenanthera peregrina. International Journal of Phytoremediation, v.22, n.13, p.1-10, 2020. DOI: http://doi.org/10.1080/15226514.2020.1775548

HACK, C. M.; PORTA, M.; SCHÄUFELE, R.; GRIMOLDI, A. A.. Arbuscular mycorrhiza mediated effects on growth, mineral nutrition and biological nitrogen fixation of Melilotus alba Med. in a subtropical grassland soil. Applied Soil Ecology, v.134, p.38-44, 2019. DOI:

http://doi.org/10.1016/j.apsoil.2018.10.008 
HAILEMARIAM, M.; BIRHANE, E.; GEBRESAMUEL, G.; GEBREKIROS, A.; DESTA, Y.; ALEMAYEHU, A.; MURUTS, H.; ARAYA, T.; NORGROVE, L.. Arbuscular mycorrhiza effects on Faidherbia albida (Del.) A. Chev. growth under varying soil water and phosphorus levels in Northern Ethiopia. Agroforestry Systems, v.92, n.2, p.485-498, 2018. DOI: http://doi.org/10.1007/s10457-017-0146-x

HARO, H.; SANON, K. B.; LE ROUX, C.; DUPONNOIS, R.; TRAORÉ, A. S.. Improvement of cowpea productivity by rhizobial and mycorrhizal inoculation in Burkina Faso. Symbiosis, v.74, n.2, p.107-120, 2018. DOI: http://doi.org/10.1007/s13199-017-0478-3

HIGGINS, S. A.; OVEREEM, I.; ROGERS, K. G.; KALINA, E. A.. River linking in India: Downstream impacts on water discharge and suspended sediment transport to deltas. Elementa: Science of the Anthropocene, v.6, n.1, 2018. DOI: http://doi.org/10.1525/elementa.269

IDRI, A.; ABNANE, I.; ABRAN, A.. Evaluating Pred (p) and standardized accuracy criteria in software development effort estimation. Journal of Software: Evolution and Process, v.30, n.4, p.e1925, 2018.

JANOUŠKOVÁ, M.; PÜSCHEL, D.; HUJSLOVÁ, M.; SLAVÍKOVÁ, R.; JANSA, J.. Quantification of arbuscular mycorrhizal fungal DNA in roots: how important is material preservation?. Mycorrhiza, v.25, n.3, p.205-214, 2015. DOI: http://doi.org/10.1007/s00572-014-0602-7

KEELE, S.. Guidelines for performing systematic literature reviews in software engineering. Technical report, Ver. 2.3 EBSE Technical Report. EBSE, 2007.

KOHLER, J.; CARAVACA, F.; AZCÓN, R.; DÍAZ, G.; ROLDÁN, A.. The combination of compost addition and arbuscular mycorrhizal inoculation produced positive and synergistic effects on the phytomanagement of a semiarid mine tailing. Science of the Total Environment, v.514, p.42-48, 2015. DOI: http://doi.org/10.1016/j.scitotenv.2015.01.085

LARRAINZAR, E.; WIENKOOP, S.. A proteomic view on the role of legume symbiotic interactions. Frontiers in Plant Science, v.8, 2017. DOI:

http://doi.org/10.3389/fpls.2017.01267

MAHDHI, M.; TOUNEKTI, T.; KHEMIRA, H.. Effects of prosopis juliflora on germination, plant growth of sorghum bicolor, mycorrhiza and soil microbial properties. Allelopathy Journal, v.46, n.2, p.265-276, 2019. DOI: http://doi.org/10.26651/allelo.j/2019-46-2-1214

MAIA, J. C.; COUTINHO, J. F. V.; SOUSA, C. R.; BARBOSA, R. G. B.; MOTA, F. R. N.; MARQUES, M. B.; SILVA, R. R. L.; LIMA, R. B. S.. Assistive technologies for demented elderly: a systematic review. Acta Paul Enferm., v.31, n.6, p.651-658, 2018.

MAIA, R. P. C.. Crescimento e desenvolvimento económico global sustentado. Revista de Gestão dos Países de Língua Portuguesa, v.15, n.1, p.65-77, 2016.

MALKOV, N.; FLIEGMANN, J.; ROSENBERG, C.; GASCIOLLI, V.; TIMMERS, A. C. J.; NURISSO, A.; CULLIMORE, J.; BONO, J. J. Molecular basis of lipo-chitooligosaccharide recognition by the lysin motif receptor-like kinase LYR3 in legumes. Biochemical Journal, v.473, n.10, p.1369-1378, 2016. DOI: http://doi.org/10.1042/BCJ20160073

MARZBAN, Z.; FARYABI, E.; TORABIAN, S.. Effects of arbuscular mycorrhizal fungi and Rhizobium onion content and root characteristics of green bean and maize under intercropping. Acta Agriculturae Slovenica, v.109, n.1, p.7988, 2017. DOI: http://doi.org/10.14720/aas.2017.109.1.08

MEDEIROS, I. L.; VIEIRA, A.; BRAVIANO, G.; GONÇALVES, B. S.. Revisão Sistemática e Bibliometria facilitadas por um Canvas para visualização de informação. InfoDesign Revista Brasileira de Design da Informação, v.12, n.1, p.93110, 2015.

MENEZES, K. M. S.; SILVA, D. K. A.; QUEIROZ, M. A. A.; FÉLIX, W. P.; YANO-MELO, A. M.. Arbuscular mycorrhizal fungal communities in buffelgrass pasture under intercropping and shading systems in Brazilian semiarid conditions. Agriculture, Ecosystems and Environment, v.230, p.55-67, 2016. DOI: http://doi.org/10.1016/i.agee.2016.05.024

MIRANDA, J. C. C.; MIRANDA, L. N.; VILELA, L.; VARGAS, M. A.; CARVALHO, A. M.. Manejo da micorriza arbuscular por meio da rotação de culturas nos sistemas agrícolas do Cerrado. Embrapa Cerrados-Comunicado Técnico (INFOTECA-E), 2001.

MONTE, E.; BETTIOL, W.; HERMOSA, R.. Trichoderma e seus mecanismos de ação para o controle de doenças de plantas. Embrapa Meio Ambiente 2019.

NAGAE, M.; TAKEDA, N.; KAWAGUCHI, M.. Common symbiosis genes CERBERUS and NSP1 provide additional insight into the establishment of arbuscular mycorrhizal and root nodule symbioses in Lotus japonicus. Plant Signaling and Behavior, v.9, 2015. DOI: http://doi.org/10.4161/psb.28544

OCTAVIANO, F. R.; FELIZARDO, K. R.; MALDONADO, J. C.; FABBRI, S. C. P. F.. Semi-automatic selection of primary studies in systematic literature reviews: is it reasonable?. Empirical Software Engineering, v.20, n.6, p.1898-1917, 2015. DOI: http://doi.org/10.1007/s10664-014-9342-8

OLIVEIRA, R. S.; CARVALHO, P.; MARQUES, G.; FERREIRA, L.; NUNES, M.; ROCHA, I.; MA, Y.; CARVALHO, M. F.; VOSÁTKA, M.; FREITAS, H.. Increased protein content of chickpea (Cicer arietinum L.) inoculated with arbuscular mycorrhizal fungi and nitrogen-fixing bacteria under water deficit conditions. Journal of the Science of Food and Agriculture, v.97, n.13, p.4379-4385, 2017. DOI: http://doi.org/10.1002/jsfa.8201

PALTA, S.; GENC-LERMI, A.; OZTURK, H.. Determination of arbuscular mycorrhizal fungi at different altitudinal gradients. Fresenius Environmental Bulletin, v.27, n.10, p.7045-7053, 2018.

PÜSCHEL, D.; JANOUŠKOVÁ, M.; VOŘÍŠKOVÁ, A.; GRYNDLEROVÁ, H.; VOSÁTKA, M.; JANSA, J.. Arbuscular mycorrhiza stimulates biological nitrogen fixation in two Medicago spp. through improved phosphorus acquisition. Frontiers in Plant Science, v.8, p.10.3389, 2017. DOI: http://doi.org/10.3389/fpls.2017.00390

REIS, R. J. A.; CAMPOS, S. A.; MARTINS, G. S. L.; JESUS, E. L.; BASTIANI, M. L. R.; CAMPOS, A. N. R.. Efeitos de plantas de cobertura nas associações do milho (Zea Mays L.) com fungos benéficos do solo. Revista Brasileira de Agropecuária Sustentável, v.2, n.2, p.75-80, 2012. DOI: http://doi.org/10.21206/rbas.v2i2.169

REN, C. G.; BAI, Y. J.; KONG, C. C.; BIAN, B.; XIE, Z. H. Synergistic Interactions Between Salt-tolerant Rhizobia and Arbuscular Mycorrhizal Fungi on Salinity Tolerance of 
Sesbania cannabina Plants. Journal of Plant Growth Regulation, v.35, n.4, p.1098-1107, 2016. DOI: http://doi.org/10.1007/s00344-016-9607-0

RIBEIRO, C. S.; ROCHA, E. G.. Externalidades negativas decorrentes do uso de agrotóxicos e a insegurança alimentar: uma análise da atuação do Supremo Tribunal Federal. Revista de Direito Agrário e Agroambiental, v.3, n.1, p.23-41, 2017.

RIEGLER, M.. Insect threats to food security. Science, v.361, n.6405, p.846-846, 2018. DOI:

http://doi.org/10.1126/science.aau7311

ROCHA, I.; MA, Y.; VOSÁTKA, M.; FREITAS, H.; OLIVEIRA, R. S.. Growth and nutrition of cowpea (Vigna unguiculata) under water deficit as influenced by microbial inoculation via seed coating. Journal of Agronomy and Crop Science, v.205, n.5, p.447-459, 2019. DOI: http://doi.org/10.1111/jac.12335

ROCKSTROM, J.; WILLIAMS, J.; DAILY, G.; NOBLE, A.; MATTHEWS, N.; GORDON, L.; WETTERSTRAND, H.; DECLERK, F.; SHAH, M.; STEDUTO, P.; FRAITURE, C.; HATIBU, N.; UNVER, O.; BIRD, J.; SIBANDA, L.; SMITH, J.. Sustainable intensification of agriculture for human prosperity and global sustainability. Ambio, v.46, n.1, p.4-17, 2017.

ROSA, H. V.. Tecnologias digitais e educação: os dispositivos móveis nas políticas públicas de inserção das tecnologias na escola. Salvador: UFBA, 2017.

ROTHER, E. T.. Revisão sistemática $X$ revisão narrativa. Acta Paulista de Enfermagem, v.20, n.2, p.5-6, 2007

SÁNCHEZ, I. R.; WILLIAMS, A. M.; ANDREU, H. G.. Customer Resistance to Tourism Innovations: Entrepreneurs' Understanding and Management Strategies. Journal of Travel Research, v.59, n.3, p.450-464, 2020. DOI: http://doi.org/10.1177/0047287519843188

SANTOS, N. C. S.; SILVA, W. A.. Desafios e possibilidades da sustentabilidade na agricultura. Revista GeoSertões, v.4 n.7, p.10-25, 2019.

STEC, N.; BANASIAK, J.; JASIŃSKI, M.. Abscisic acid - an overlooked player in plant-microbe symbioses formation?. Acta Biochimica Polonica, v.63, n.1, p.53-58, 2016. DOI: http://doi.org/10.18388/abp.2015 1210

TIKKA, C.; VERBEEK, J.; KATEMAN, E.; MORATA, T. C.; DRESCHLER, W.; FERRITE, S.. Revisão sistemática e metanálise Cochrane de intervenções para prevenção de perda auditiva ocupacional induzida por ruído - abreviada. CoDAS, v.32, n.2, 2020. DOI: http://doi.org/10.1590/2317$1782 / 20192019127$

VAN ECK, N. J.; WALTMAN, L.. Citation-based clustering of publications using CitNetExplorer and VOSviewer. Scientometrics, v.111, n.2, p.1053-1070, 2017.
VENKATESHWARAN, M.; JAYARAMAN, D.; CHABAUD, M.; GENRE, A.; BALLOON, A. J.; MAEDA, J.; FORSHEY, K.; OS, D. D.; KWIEDIEN, N. W.; COON, J. J.; BARKER, D. G.; ANÉ, J.-M. A role for the mevalonate pathway in early plant symbiotic signaling. Proceedings of the National Academy of Sciences of the United States of America, v.112, n.31, p.9781-9786, 2015. DOI: http://doi.org/10.1073/pnas.1413762112

WALTMAN, L.; VAN ECK, N. J.; NOYONS, E. C. M.. A unified approach to mapping and clustering of bibliometric networks. Journal of Informetrics, v.4, n.4, p.629-635, 2010. DOI: http://doi.org/10.1016/i.joi.2010.07.002

WONG, D.. VOSviewer. Technical Services Quarterly, v.35, n.2, p.219-220, 2018. DOI: http://doi.org/10.1080/07317131.2018.1425352

XIAO, B.; JESPERSEN, D.. Morphological and Physiological Responses of Seashore Paspalum and Bermudagrass to Waterlogging Stress. Journal of the American Society for Horticultural Science, v.144, n.5, p.305-313, 2019. DOI: http://doi.org/10.21273/JASHS04737-19

XIAO, D.; TAN, Y.; LIU, X.; YANG, R.; ZHANG, W.; HE, X.; WANG, K.. Effects of different legume species and densities on arbuscular mycorrhizal fungal communities in a karst grassland ecosystem. Science of the Total Environment, v.678, p.551-558, 2019. DOI: http://doi.org/10.1016/j.scitotenv.2019.04.293

XUE, L.; ALMARIO, J.; FABIAŃSKA, I.; SARIDIS, G.; BUCHER, $M$.. Dysfunction in the arbuscular mycorrhizal symbiosis has consistent but small effects on the establishment of the fungal microbiota in Lotus japonicus. New Phytologist, v.224, n.1, p.409-420, 2019. DOI: http://doi.org/10.1111/nph.15958

YANG, Y.; DENG, J.; ZHANG, M.; LI, Y.; LIU, W.. The synchronicity and difference in the change of suspended sediment concentration in the Yangtze River Estuary. Journal of Geographical Sciences, v.25, n.4, p.399-416, 2015.

ZAMBOLIM, L.; VENTURA, J.; ZANÃO JUNIOR, L.. Efeito da Nutrição mineral no controle de Doenças de Plantas. 2012.

ZHANG, H.; ZHAO, Z.; MA, G.; SUN, L.. Quantitative evaluation of soil anti-erodibility in riverbank slope remediated with nature-based soil bioengineering in Liaohe River, Northeast China. Ecological Engineering, v.151, p.105840, 2020. DOI: http://doi.org/10.1016/j.ecoleng.2020.105840

ZHANGA, Z.; CAO, L.; ZHU, Z.; HE, C.; XIANG, H.; XU, L.; SUN, C.; LIN, C.; YANG, H.; LI, K.. Evaluation on soil bioengineering measures in agricultural areas: Poorer durability of wooden structures and better aboveground habitat improvements. Ecological Engineering, v.129, p.1-10, 2019. DOI: http://doi.org/10.1016/i.ecoleng.2019.01.004

A CBPC - Companhia Brasileira de Produção Científica (CNPJ: 11.221.422/0001-03) detém os direitos materiais desta publicação. Os direitos referem-se à publicação do trabalho em qualquer parte do mundo, incluindo os direitos às renovações, expansões e disseminações da contribuição, bem como outros direitos subsidiários. Todos os trabalhos publicados eletronicamente poderão posteriormente ser publicados em coletâneas impressas sob coordenação da Sustenere Publishing, da Companhia Brasileira de Produção Científica e seus parceiros autorizados. Os (as) autores (as) preservam os direitos autorais, mas não têm permissão para a publicação da contribuição em outro meio, impresso ou digital, em português ou em tradução. 